\title{
Correction to: Calculating and Interpreting ICERs and Net Benefit
}

\author{
Mike Paulden ${ }^{1}$ (1)
}

Published online: 19 August 2020

(c) Springer Nature Switzerland AG 2020

\section{Correction to: PharmacoEconomics}

https://doi.org/10.1007/s40273-020-00914-6

In Table 6, for Strategy F, the Health loss (QALYs) should be 0.5 rather than 2 and the NHB (QALYs) should be 5.5 rather than 4 . These errors do not affect the ranking of the strategies or the overall findings of the paper.

The original article can be found online at https://doi.org/10.1007/ s40273-020-00914-6.

Mike Paulden

paulden@ualberta.ca

1 School of Public Health, University of Alberta, 3-300

ECHA, 1140587 Ave NW, Edmonton, AB T6G 1C9,

Canada 